\title{
KARAKTERISTIK GANGGUAN NYERI SEBAGAI GEJALA NON-MOTORIK PADA PENYAKIT PARKINSON
}

\author{
PAIN CHARACTERISTICS AS NON-MOTOR SYMPTOM IN PARKINSON DISEASE
}

\author{
Vincent Ongko Wijaya, * Rizaldy Taslim Pinzon*
}

\section{ABSTRACT}

Introduction: Parkinson's Disease (PD) as a progressive neurodegenerative disorder of the central nervous system that has motor and non-motor symptom. Pain is one of the most common non-motor symptom of PD and has a significant impact in impairment of patients quality of life, therefore understanding the characteristics of pain in $P D$ is needed.

Aim: To obtain the characteristics of pain disorder in Parkinson's Disease patients.

Method: This was an observational descriptive study with cross sectional design in PD patients Bethesda Hospital in Yogyakarta from January to March 2018. The characteristics of pain in PD patients was assessed based on anamnesis and King's Parkinson Disease Pain Scale (KPPS) questionnaire filling.

Result: Thirty-one PD patients were assessed with majority being male (54.8\%), >70 years old (45.15\%), H\&Y stage III (64.5\%), and disease duration 1-2 years (41.9\%). Pain was present in over $70.96 \%$ patients mostly musculoskeletal pain (45.2\%), followed by nocturnal pain (25.8\%) and radicular pain (25.8\%).

Discussion: The prevalence of pain as non-motor symptom of PD patients with majority in $H \& Y$ stage III was $70.96 \%$, with the most common types were musculoskeletal pain, nocturnal pain, and radicular pain.

Keywords: Pain, parkinson's disease

\section{ABSTRAK}

Pendahuluan: Penyakit Parkinson (PP) adalah kelainan neurodegeneratif sistem saraf pusat (SSP) yang progresif dengan gejala motorik dan non-motorik. Nyeri merupakan salah satu manifestasi non-motorik tersering pada PP, serta berperan cukup signifikan terhadap penurunan kualitas hidup pada pasien, sehingga diperlukan pemahaman mengenai karakteristik nyeri pada PP.

Tujuan: Mengetahui prevalensi dan karakteristik gangguan nyeri pada pasien PP.

Metode: Penelitian deskriptif observasional secara potong lintang terhadap pasien PP di RS Bethesda, Yogyakarta, pada bulan Januari hingga Maret 2018. Karakteristik nyeri pada pasien PP dinilai berdasarkan hasil anamnesis melalui pengisian kuesioner King's Parkinson Disease Pain Scale (KPPS).

Hasil: Didapatkan 31 subjek PP yang mayoritas laki-laki (54,8\%) berusia $>70$ tahun (45,1\%), berada stadium III (64,5\%), dan durasi sakit 1-2 tahun (41,9\%). Nyeri ditemukan pada 70,96\% subjek, berupa nyeri muskuloskeletal (45,2\%), nyeri nokturnal $(25,8 \%)$, dan nyeri radikuler $(25,8 \%)$.

Diskusi: Prevalensi nyeri sebagai gejala non-motorik pada PP yang mayoritas berada pada stadium III adalah $70,96 \%$ dengan karakteristik nyeri terbanyak berupa nyeri muskuloskeletal, nyeri nokturnal, dan nyeri radikular.

Kata kunci: Nyeri, penyakit Parkinson

*FK Universitas Kristen Duta Wacana, Yogyakarta. Korespondensi: vincent_wijaya007@yahoo.com.

\section{PENDAHULUAN}

Penyakit Parkinson (PP) adalah kelainan neurodegeneratif sistem saraf pusat (SSP) yang progresif dengan gejala motorik, non-motorik, dan perubahan perilaku akibat perubahan patologik pada neuron dopaminergik di substansia nigra. Adapun nyeri adalah pengalaman sensorik dan emosional yang tidak menyenangkan akibat kerusakan jaringan, baik aktual maupun potensial, atau digambarkan dalam bentuk kerusakan tersebut. ${ }^{1-2}$

Nyeri pada PP merupakan gejala yang sering muncul, kompleks, dan menganggu kualitas hidup pasien, namun seringkali terlambat didiagnosis dan tidak diobati secara sistematis. Diperkirakan sekitar 7 sampai 10 juta orang diseluruh dunia terdiagnosis PP dan insidennya akan terus meningkat seiring bertambahnya usia. Buhmann dkk menunjukkan prevalensi nyeri sebesar $95,4 \%$ dari pasien PP, namun hanya $22,3 \%$ pasien yang dapat terdiagnosis, sehingga terlambat untuk ditatalaksana. Demikian pula Ford menunjukkan hingga $80 \%$ pasien PP mengalami nyeri kronik yang berkepanjangan. ${ }^{3-6}$

Saat ini terdapat alat ukur skala nyeri spesifik yang tervalidasi secara internasional untuk 


\section{KING'S PARKINSON DISEASE PAIN SCALE VERSI BAHASA INDONESIA}

No ID Pasien:

Inisial:

Tanggal Lahir:

Skala ini dirancang untuk mendeskripsikan secara akurat jenis dan pola rasa nyeri yang dialami pasien selama satu bulan terakhir yang disebabkan oleh penyakit Parkinson atau pengobatan yang terkait penyakit Parkinson.

Setiap gejala diberi skor sesuai dengan

Keparahan: $0=$ tidak ada

1 = ringan (terdapat gejala tetapi hanya menimbulkan sedikit kesulitan atau gangguan bagi pasien),

2 = sedang (cukup menimbulkan kesulitan atau gangguan bagi pasien),

3 = berat (gejala menjadi sumber utama kesulitan atau gangguan bagi pasien).

Frekuensi: $0=$ Tidak pernah

1 = Jarang $(<1 /$ minggu $)$,

2 = Kadang-kadang $(1 /$ minggu $)$,

3 = sering (beberapa kali seminggu),

4 = sangat sering (setiap hari atau sepanjang waktu).

\section{Domain 1: Nyeri Muskuloskeletal}

1. Apakah pasien mengalami nyeri di sekitar persendiannya? (termasuk nyeri artritis)

$\frac{\text { Keparahan }}{(0-3)} \quad \frac{\text { Frekuensi }}{(0-4)} \quad \underline{\text { Frekuensi }}$

\section{SKOR TOTAL Domain 1:}

\section{Domain 2: Nyeri Kronis}

2. Apakah pasien mengalami nyeri di tubuh bagian dalam? (Nyeri konstan yang tidak terlalu sakit- nyeri sentral)

3. Apakah pasien mengalami nyeri yang berkaitan dengan organ dalam? (Contohnya nyeri di sekitar hati, perut atau usus - nyeri viseral)

\section{SKOR TOTAL Domain 2:}

\section{Domain 3: Nyeri yang Terkait dengan Fluktuasi}

4. Apakah pasien mengalami nyeri diskinetik? (Nyeri yang terkait dengan gerakan involunter yang abnormal) 
5. Apakah pasien mengalami off period dystonia pada regio tertentu? (pada area distonia)

6. Apakah pasien mengalami off period pain? (nyeri diseluruh tubuh atau area yang jauh dari dampak distonia)

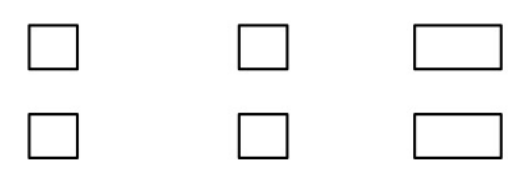

\section{SKOR TOTAL Domain 3:}

\section{Domain 4: Nyeri Nokturnal}

7. Apakah pasien mengalami nyeri terkait dengan gerakan sentakan kaki di malam hari (PLM) atau sensasi tidak nyaman seperti terbakar pada kaki yang membaik seiring gerakan ( $R L S)$ ?

8. Apakah pasien mengalami nyeri terkait dengan kesulitan menghadap samping saat tidur di malam hari?

\section{SKOR TOTAL Domain 4:}

\section{Domain 5: Nyeri Oro-fasial}

9. Apakah pasien mengalami nyeri ketika mengunyah?

10. Apakah pasien mengalami nyeri karena giginya yang bergemeretak saat tidur malam?

11. Apakah pasien mengalami sensasi mulut seperti terbakar?
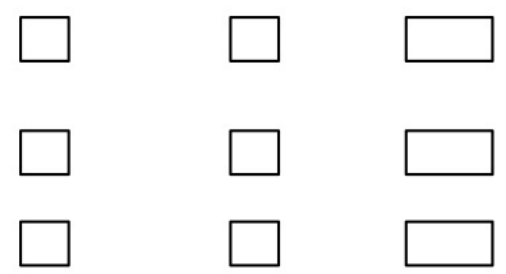

SKOR TOTAL Domain 5:

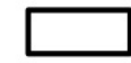

Domain 6: Perubahan warna; Edema/pembengkakan

12. Apakah pasien mengalami nyeri seperti terbakar pada anggota gerak tubuh? (sering diasosiasikan dengan pembengkakan atau pengobatan dopaminergik)

13. Apakah pasien mengalami nyeri di perut bagian bawah?

SKOR TOTAL Domain 6:
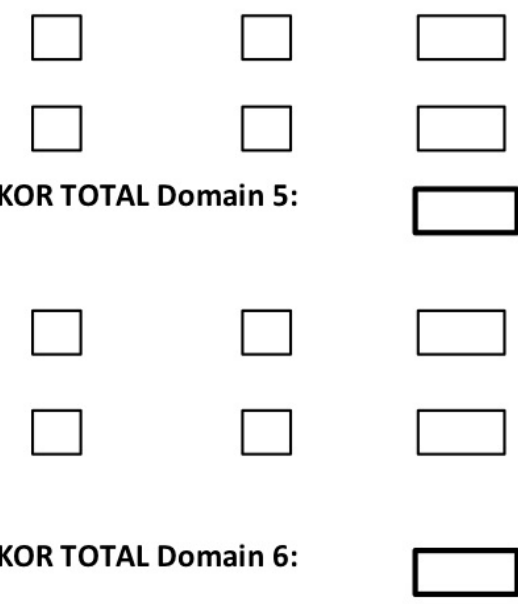

\section{Domain 7: Nyeri Radikuler}

14. Apakah pasien mengalami nyeri yang menghentak/kesemutan hingga ke anggota gerak tubuh?
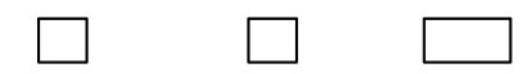

SKOR TOTAL Domain 7:

\section{Komentar:}

Gambar 1. Kuesioner King's Parkinson's Disease Pain Scale Versi Bahasa Indonesia ${ }^{8}$ 
pasien PP pertama kali pada tahun 2015, King's Parkinson Disease Pain Scale (KPPS) yang dapat mengklasifikasikan tipe-tipe nyeri pada pasien Parkinson. ${ }^{7}$ Skala ini telah diadaptasi serta telah teruji valid dan reliabel ke dalam bahasa Indonesia. ${ }^{8}$

Keluhan nyeri pada pasien PP merupakan salah satu manifestasi non-motorik yang cukup sering dan mengganggu pada pasien PP, namun studi epidemiologi di Indonesia masih kurang memadai, sehingga perlu dilakukan penelitian ini.

\section{TUJUAN}

Mengetahui prevalensi dan gambaran karakteristik gangguan nyeri pada pasien PP di RS Bethesda, Yogyakarta.

\section{METODE}

Desain penelitian ini adalah observasional potong lintang terhadap semua pasien PP yang berobat ke Poli Saraf RS Bethesda, Yogyakarta, pada bulan Januari hingga Maret 2018. Kriteria inklusi adalah pasien berusia $>40$ tahun yang rutin mengonsumsi obat anti-parkinson dan bersedia mengikuti penelitian. Adapun kriteria eksklusi adalah pasien dengan gangguan komunikasi secara baik, seperti demensia atau afasia.

Setiap subjek dikelompokkan berdasarkan stadium penyakit menggunakan skala Hoehn and Yahr (H\&Y). Gangguan nyeri dinilai berdasarkan kuesioner KPPS yang mengukur nyeri selama sebulan terakhir. Kuesioner tersebut terdiri dari 14 item pertanyaan dan 7 domain yang terdiri dari; item 1 untuk menilai nyeri muskuloskeletal, item 2 dan 3 untuk nyeri kronik, item 4-6 tentang nyeri yang terkait dengan fluktuasi, item 7 dan 8 untuk menilai nyeri nokturnal, item 9-11 pada nyeri orofasial, item 12 dan 13 untuk menilai perubahan warna dan edema/ pembengkakan, serta item 14 untuk nyeri radikuler (Gambar 1).

Penelitian ini telah disetujui oleh Komite Etik Penelitian Kesehatan Fakultas Kedokteran Universitas Kristen Duta Wacana dengan nomor 547/C.16/FK/2017. Analisis data menggunakan perangkat SPSS.

\section{HASIL}

Data karakteristik sampel (Tabel 1) mayoritas berada pada rentang usia $>70$ tahun $(45,1 \%)$ dengan jenis kelamin terbanyak laki-laki $(54,8 \%)$, stadium penyakit III $(64,5 \%)$, dan durasi sakit dalam rentang 1-2 tahun $(41,9 \%)$.

Tabel 1. Karakteristik Subjek Penelitian $(n=31)$

\begin{tabular}{lc}
\hline Karakteristik & n (\%) \\
\hline Usia & $1(3,3)$ \\
- $40-50$ tahun & $3(9,7)$ \\
- 51-60 tahun & $13(41,9)$ \\
- $61-70$ tahun & $14(45,1)$ \\
- $>70$ tahun & \\
Jenis kelamin & $17(54,8)$ \\
- Laki-laki & $14(45,2)$ \\
- Perempuan & \\
Stadium & \\
- I & $0(0)$ \\
- II & $9(29)$ \\
- III & $20(64,5)$ \\
- IV & $2(6,5)$ \\
- V & $0(0)$ \\
Durasi sakit & \\
- $\leq 1$ tahun & \\
- 1-2 tahun & \\
- 2-3 tahun & $13(41,9)$ \\
- 3 tahun & $10(32,3)$ \\
\hline
\end{tabular}

Tipe nyeri tertinggi berdasarkan ranah KPPS (Tabel 2) secara berurutan adalah nyeri muskuloskeletal (45,2\%), nyeri nokturnal $(25,8 \%)$, nyeri radikuler $(25,8 \%)$, perubahan warna; edema/ pembengkakan $(19,4 \%)$, nyeri kronik $(16,1 \%)$, dan nyeri yang terkait fluktuasi $(6,5 \%)$, tanpa ada nyeri orofasial.

Tabel 2. Tipe Nyeri berdasarkan Ranah KPPS $(n=31)$

\begin{tabular}{lc}
\hline \multicolumn{1}{c}{ Ranah KPPS } & n (\%) \\
\hline 1. Nyeri muskuloskeletal & $14(45,2)$ \\
2. Nyeri kronik & $5(16,1)$ \\
3. Nyeri terkait fluktuasi & $2(6,5)$ \\
4. Nyeri nokturnal & $8(25,8)$ \\
5. Nyeri orofasial & $0(0)$ \\
6. Perubahan warna; edema/pembengkakan & $6(19,4)$ \\
7. Nyeri radikuler & $8(25,8)$ \\
\hline
\end{tabular}

KPPS: King's Parkinson Disease Pain Scale. 


\section{PEMBAHASAN}

Didapatkan subjek laki-laki lebih banyak dibanding perempuan $(54,8 \%$ vs $45,2 \%)$ dengan rentang usia terutama $>70$ tahun $(45,1 \%)$ dan paling rendah pada rentang usia 40-50 tahun $(3,3 \%)$. Liu dkk mendapatkan bahwa insidens dan prevalensi PP meningkat seiring dengan pertambahan usia dan cenderung lebih tinggi pada laki-laki dibandingkan perempuan dan bahwa gender laki-laki merupakan faktor prediktor yang cukup signifikan untuk prevalensi PP. ${ }^{9}$ Studi terdahulu juga menunjukkan mayoritas pasien PP berusia $>60$ tahun dengan peningkatan insidens dan prevalensi setelah usia 50 tahun. Penderita yang berusia $<50$ tahun dianggap memiliki onset awal dari PP. ${ }^{10-11}$

Durasi sakit subjek terbanyak dalam rentang 1-2 tahun (41,9\%) diikuti 2-3 tahun $(32,3 \%)$, dan durasi $>3$ tahun (16,1\%). Studi metaanalisis Enders dkk yang melibatkan 178.169 pasien menyebutkan bahwa mayoritas pasien memiliki durasi $<5$ tahun sebagai yang tertinggi (40\%) diukur dari onset pertama kali menderita PP, diikuti rentang durasi 5-9 tahun $(31 \%)$ dan $>9$ tahun $(29 \%){ }^{12}$

Mayoritas subjek penelitian ini berada pada stadium III (64,5\%) dan II (29\%). Chaudhuri dkk mendapatkan bahwa skor KPPS meningkat secara signifikan seiring dengan keparahan penyakit berdasarkan skala H\&Y. Hal ini menunjukkan perkembangan keparahan penyakit diikuti juga oleh peningkatan intensitas nyeri pada pasien PP, dan berpengaruh secara signifikan terhadap kualitas hidup pasien. ${ }^{\text {? }}$

Penelitian ini mendapatkan keluhan nyeri pada subjek dengan PP dalam 1 bulan terakhir sebanyak $71,2 \%$. Angka ini lebih tinggi dari pada Beiske dkk yang menunjukkan prevalensi nyeri sebesar $60 \%$. Penelitian sebelumnya melaporkan karakteristik nyeri pada pasien PP berdasarkan klasifikasi Ford yang mengkategorikan nyeri menjadi 4 tipe, dengan tipe nyeri terbanyak merupakan nyeri muskuloskeletal (70\%), diikuti nyeri distonik (40\%), nyeri radikularneuropatik $(20 \%)$, dan nyeri neuropatik pusat $(10 \%){ }^{13}$

Adapun karakteristik nyeri terbanyak pada penelitian ini ditempati oleh ranah 1 yaitu nyeri muskuloskeletal $(45,2 \%)$ diikuti oleh nyeri nokturnal
$(25,8 \%)$, dan nyeri radikuler $(25,8 \%)$. Data ini mirip dengan Rizos dkk tentang skala KPPS, bahwa sebagian besar tipe nyeri pada pasien PP merupakan nyeri muskuloskeletal $(80,1 \%)$ diikuti nyeri radikuler $(25,3 \%)$ bila dibandingkan dengan $\operatorname{kontrol}(\mathrm{p}<0,05) .{ }^{14}$

Studi meta-analisis oleh Rana dkk tentang karakteristik nyeri melaporkan bahwa nyeri pada pasien PP lebih cenderung menyebabkan depresi dan penurunan kualitas hidup pada pasien. Sebagian besar pasien yang mengalami gangguan nyeri tersebut juga melaporkan manajemen nyeri yang kurang baik serta penggunaan analgesik yang tidak tepat. ${ }^{13}$ Valkovic dkk melaporkan prevalensi nyeri pada pasien PP mencapai $76 \%$ yang terdiri dari berbagai tipe nyeri, seperti nyeri muskuloskeletal dan nyeri radikuler. Hal ini menunjukkan bahwa semua tipe nyeri pada PP lebih cenderung muncul di stadium lanjut dan memburuk seiring dengan progresivitas penyakit. ${ }^{15-16}$

Gejala non-motorik pada PP telah menjadi perhatian peneliti dalam beberapa tahun terakhir. Nyeri pada PP muncul pada fase preklinik dan stadium awal dari penyakit menyebabkan gangguan kualitas hidup pada pasien. Beberapa penelitian menunjukkan korelasi antara nyeri pada PP terhadap stadium penyakit dan kualitas hidup pasien.

Penelitian ini memiliki beberapa keterbatasan antara lain jumlah sampel yang tidak terlalu banyak, sehingga kurang merepresentasikan gambaran nyeri pada PP di populasi yang lebih besar. Peneliti juga tidak meneliti komorbid dan terapi sebagai salah satu faktor yang dapat memengaruhi hasil penelitian. Oleh karena itu diperlukan studi lanjutan untuk mengukur hubungan antara berbagai tipe nyeri pada PP terhadap penyakit komorbid dan pengobatan yang diberikan, mengingat nyeri merupakan gejala yang berfluktuasi pada PP.

\section{KESIMPULAN}

Prevalensi nyeri sebagai gejala non-motorik pada PP yang mayoritas berada pada stadium III di RS Bethesda, Yogyakarta adalah 70,96\% dengan karakteristik nyeri terbanyak berupa nyeri muskuloskeletal, nyeri nokturnal, dan nyeri radikular.

\section{DAFTAR PUSTAKA}

1. Johnson KE. Approach to the patient with Parkinson disease. Primary Care: Clinics in Office Practice. 2015;42(2):205-15. 
2. Kumar KH, Elavarasi P. Definition of pain and classification of pain disorders. JCI Insights. 2016;3:87-90.

3. Ha AD, Jankovic J. Pain in Parkinson's disease. Mov Disord. 2012;27(4):485-91.

4. National Parkinson Foundation. Parkinson's disease overview; 2014.

5. Buhmann C, Wrobel N, Grashorn W, Fruendt O, Wesemann K, Diedrich S, dkk. Pain in Parkinson's disease: a cross sectional survey of its prevalence, specifics, and therapy. J Neurol. 2017;264(4):758-69.

6. Ford B. Pain in Parkinson's disease. Mov Disord. 2010;25(Suppl 1):S98-S103.

7. Chaudhuri K, Rizos A, Trenkwalder C, Rascol O, Pal S, Martino D, dkk. King's Parkinson's disease pain scale, the first scale for pain in PD: an international validation. Mov Disord. 2015;30(12):1623-31.

8. Wijaya VO, Pinzon RT. The Reliability Study of King's Parkinson's Disease Pain Scale in Indonesian Version. Mov Disord. 2018;33(Supl 2):839-40.

9. Liu C, Li C, Lee P, Sun Y. Variations in incidence and prevalence of parkinson's disease in Taiwan: a population-based nationwide study. Parkinson's Disease. 2016;2016:8756359.

10. Willis AW. Parkinson disease in the elderly adult. Mo Med. 2013;110(5);406-10.
11. Barrett M, Hac N, Yan G, Harrison M, Wooten G. Relationship of age of onset and family history in Parkinson disease. Mov Disord. 2015;30(5):733-5.

12. Enders D, Balzer-Geldsetzer M, Riedel O, Dodel R, Wittchen H, Sensken S, dkk. Prevalence, duration and severity of parkinson's disease in germany: a combined meta-analysis from literature data and outpatient samples. European Neurology. 2017;78(34):128-36.

13. Beiske AG, Loge JH, Ronningen A, Svensson E. Pain in Parkinson's disease: prevalence and characteristics. Pain. 2009;141(1-2):173-7.

14. Martinez-Martin P, Rizos AM, Wetmore J, Antonini A, Odin P, Pal S, dkk. First comprehensive tool for screening pain in Parkinson's disease: the king's Parkinson's disease pain questionnaire. Eur J Neurol. 2018;25(10):1255-61.

15. Rana AQ, Kabir A, Jesudasan M, Siddiqui I, Khondker S. Pain in Parkinson's disease: analysis and literature review. Clin Neurol Neurosurg. 2013;115(11):23137.

16. Valkovic $\mathrm{P}$, Minar M, Singliarova H, Harsany J, Hanakova M, Martinkova J, dkk. Pain in Parkinson's disease: a cross-sectional study of its prevalence, types, and relationship to depression and quality of life. PLoS One. 2015.10(8):e0136541. 